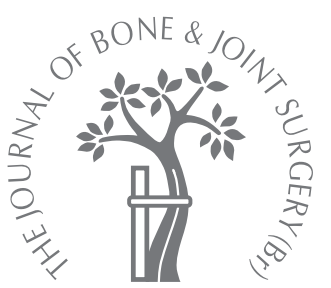

I. Udofia, F. Liu, Z. Jin, P. Roberts, P. Grigoris

From University of Leeds, Leeds, England

\title{
The initial stability and contact mechanics of a press-fit resurfacing arthroplasty of the hip
}

Finite element analysis was used to examine the initial stability after hip resurfacing and the effect of the procedure on the contact mechanics at the articulating surfaces. Models were created with the components positioned anatomically and loaded physiologically through major muscle forces. Total micromovement of less than $\mathbf{1 0} \mu \mathrm{m}$ was predicted for the press-fit acetabular components models, much below the $50 \mu \mathrm{m}$ limit required to encourage osseointegration. Relatively high compressive acetabular and contact stresses were observed in these models. The press-fit procedure showed a moderate influence on the contact mechanics at the bearing surfaces, but produced marked deformation of the acetabular components. No edge contact was predicted for the acetabular components studied.

It is concluded that the frictional compressive stresses generated by the $1 \mathrm{~mm}$ to $2 \mathrm{~mm}$ interference-fit acetabular components, together with the minimal micromovement, would provide adequate stability for the implant, at least in the immediate post-operative situation.

Resurfacing arthroplasty of the hip is becoming increasingly popular for young patients, who may require a second procedure in their lifetime. ${ }^{1-4}$ It is a conservative operation that allows preservation of bone, particularly in the proximal femur, thereby facilitating revision should it be required. Resurfacing arthroplasties have a large bearing size, similar to the natural geometry of the hip, which helps maintain stability and a normal range of movement with a reduced risk of dislocation and impingement. ${ }^{5,6}$ Various metal-on-metal hip resurfacing designs are commercially available and recent short- and medium-term clinical results have been promising. ${ }^{2,3,7-11}$

All contemporary metal-on-metal hip resurfacing designs use a cementless acetabular component. Primary stability is essential for secondary fixation through bone ingrowth. Initial stability can be influenced by the method of fixation (press-fit or adjunctive), the surgical technique, the quantity and quality of the bone, component geometry and loading conditions. ${ }^{12}$ Press-fit fixation involves inserting an acetabular component into an underreamed acetabulum, where the primary stability is achieved through the frictional compressive forces generated about the acetabular periphery. ${ }^{13-20}$ Increasing the degree of interference should result in increased stability through a reduction in the relative movement between the component and the bone. ${ }^{16,20,21}$ Most acetabular components are implanted with a diametral interference ranging between $1 \mathrm{~mm}$ and $2 \mathrm{~mm},{ }^{2,22-24}$ whereas interference values up to or beyond $4 \mathrm{~mm}$ require excessive reaming and could cause fracture. ${ }^{25}$ In contrast, a line-to-line fit (zero interference) could result in excessive movement between the component and bone, and may require some form of adjunctive fixation.

The aim of this study was to examine the stability of press-fit hip resurfacing acetabular components using the finite element method. Also, given that the interactions at the interface between the acetabular component and the bone could potentially affect the tribology of the bearing, ${ }^{26-28}$ the effects of the press-fit procedure on the contact mechanics at the articulating surfaces were also investigated.

\section{Materials and Methods}

A conceptual design of a typical commerciallyavailable metal-on-metal hip resurfacing arthroplasty (Durom, Zimmer GmbH, Winterthur, Switzerland) was examined (Fig. 1). The acetabular component had a nominal inner bearing diameter of $50.145 \mathrm{~mm}$ and a uniform thickness of $4 \mathrm{~mm}$. Fixation was by press-fit insertion. A $50 \mathrm{~mm}$ femoral head component 

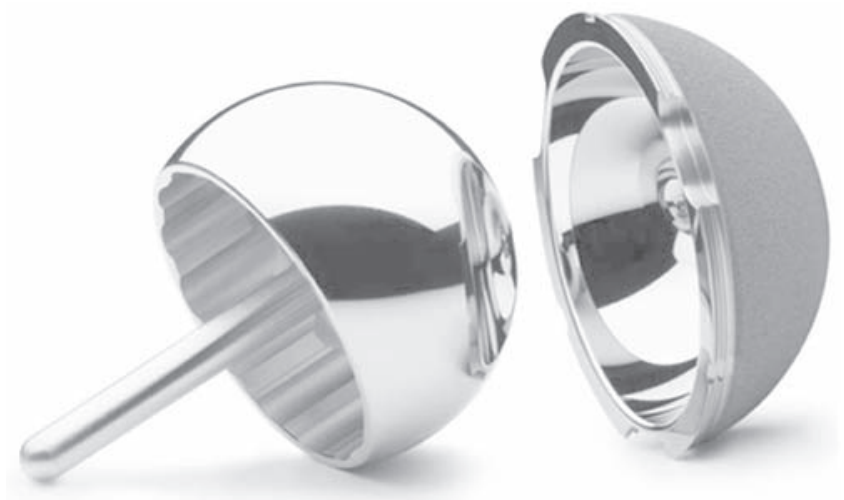

Fig. 1a

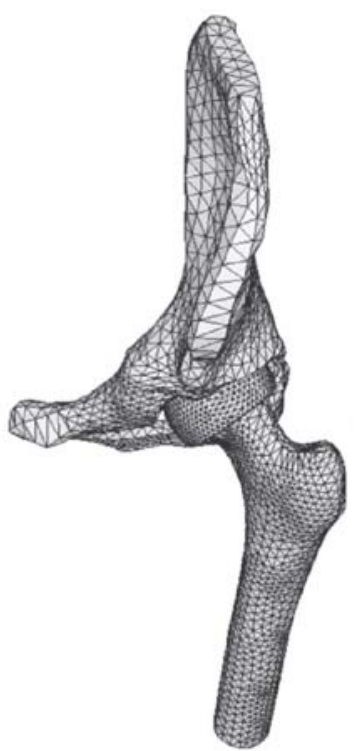

Fig. 1b

Photograph of a) the Durom hip resurfacing prosthesis (Zimmer GmbH, Winterthur, Switzerland) and b) a diagram of the three-dimensional finite-element bone model of the hip joint.

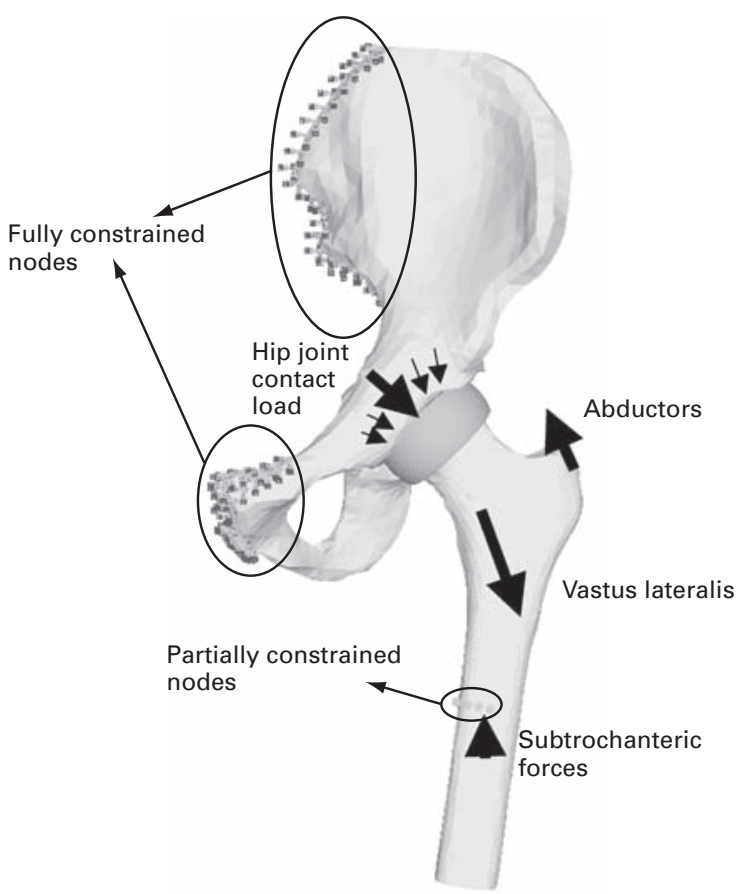

Fig. 2a

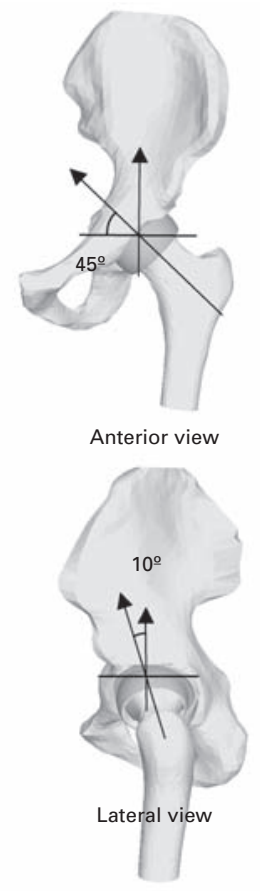

Fig. 2b
The finite-element bone model showing a) the loading conditions and boundary constraints and b) the implantation angles $\left(45^{\circ}\right.$ inclination and $10^{\circ}$ anteversion). was used, with a resulting diametrical clearance between the acetabular component and the femoral head of $145 \mu \mathrm{m}$. The femoral component was fixed into the femur with acrylic cement with the thickness ranging approximately between $1 \mathrm{~mm}$ and $1.5 \mathrm{~mm}$. The short tapered stem provided the only alignment for the femoral component.

Three-dimensional solid models of the arthroplasty were created and implanted into solid models of the hemipelvis and femoral bone obtained from the visible human project. ${ }^{29,30}$ The solid models were meshed in I-DEAS (Version 11, UGS PLM Solutions Inc., Plano, Texas). The resulting finite-element models (Fig. 2) were then solved using ABAQUS (version 6.5-1, ABAQUS Inc., Providence, Rhode Island).

The components were made of cobalt chromium alloy with an elastic modulus of $220 \mathrm{GPa}$ and Poisson's ratio of 
0.3. All the materials in the finite-element model were assumed to be homogeneous and linear elastic. ${ }^{31-35}$ The elastic modulus and Poisson's ratio for the cortical bone were $17 \mathrm{GPa}$ and 0.3 , respectively. ${ }^{36}$ The elastic modulus in the cancellous bone of the pelvis and femur was assumed to be $0.5 \mathrm{GPa}$ and $1.5 \mathrm{GPa}$, respectively, with a Poisson's ratio of $0.3 .^{36}$ The cement mantle had an elastic modulus of 2.5 GPa and a Poisson's ratio of $0.25 .^{36}$

The pelvic model consisted of cancellous bone by a uniform cortical shell $1.5 \mathrm{~mm}$ thick. The subchondral acetabular bone was assumed to have been reamed completely prior to implantation. The acetabular component was positioned anatomically in $45^{\circ}$ of abduction and $10^{\circ}$ anteversion (Fig. 2). The contact interface between the outer surface of the component and the acetabulum was modelled using surface-based contact elements with an applied friction coefficient of $0.5 .^{34,37,38}$

During surgery, seating the cementless acetabular component involves impacting it into an under-reamed acetabulum. This impaction procedure was not simulated into the finite-element model instead, the "*CLEARANCE" and "*CONTACT INTERFERENCE" formulation options available in ABAQUS were used, which simulated press-fitting by pushing apart the contact surfaces of the acetabulum and the cup by the required amount of interference. Also, pre-compression of the acetabulum was permitted, the acetabular component was assumed to be perfectly seated, and the procedure facilitated the convergence of the numerical solutions without causing large numerical errors. The finite-element models considered for this study included $1 \mathrm{~mm}$ press-fit, $2 \mathrm{~mm}$ press-fit, line-to-line, and, for purposes of comparison, a fully bonded acetabular component (all Durom), which assumed a long-term condition, with $100 \%$ osseointegration between the component and the acetabulum, a situation not normally present clinically.

On the femoral side, only the proximal third of the femur was considered for the finite-element model (Fig. 2), as it was assumed that the distal regions of the femur would have a negligible influence on the contact mechanics at the articulating surfaces or the fixation interactions at the acetabular component-bone interface. ${ }^{39-41}$ The femoral component was implanted at $45^{\circ}$ of abduction and $10^{\circ}$ anteversion (Fig. 2). The contact interfaces in the femoral model between cement and bone and cement and implant were all assumed to be perfectly bonded. Surface-based contact elements were used to model the contact between the surfaces of the femoral component and the femur.

The contact at the bearing surfaces between the femoral head and the acetabular component was modelled by frictionless surface-based contact elements to simulate a welllubricated condition. A mesh convergence study was performed to examine contact mechanics at the articulating surfaces and the stresses in bone. The finite-element models were composed of a total of approximately 80000 elements, consisting of predominantly four-node tetrahedral elements, three-noded shell elements (to mesh the cortical shell in pelvis), eight-node brick elements (to mesh the contact surfaces), and six-node wedge elements.

A fixed resultant contact force of $3200 \mathrm{~N}$ was applied to the joint through medial and anterior muscle forces and subtrochanteric forces in order to represent the mid to terminal stance loading of the gait cycle (Fig. 2). ${ }^{42,43}$ Coordinates of the muscle forces were obtained from the literature and applied to the nodes on these locations. ${ }^{44}$ The boundary conditions applied to the model were as follows (Fig. 2):

1. To simulate sacral support, the nodes situated in the sacroiliac joint were fully constrained, thus preventing their movement in any direction. The nodes within and around the pubic symphysis were also fully constrained. ${ }^{45}$

2. Nodes around a transverse section of the femur were partially constrained, allowing only one or two degrees of freedom.

In order to determine the immediate post-operative stability of the acetabular component prior to any bone ingrowth, the total relative micromovement between the component and the acetabulum was determined. Paired nodes across the acetabular component-bone interface were identified and the total relative micromovement was calculated for the duration of the analysis. ${ }^{45}$ A comparison of the total relative micromovement between the finiteelement models was made for the total percentage surface contact area experiencing micromovement above and below the $50 \mu \mathrm{m}$ threshold required for osseointegration. The maximum total relative micromovement for each of the finite-element models was also considered.

The contact mechanics at the acetabular componentbone interface and the bearing surfaces, as well as the stresses generated in the acetabulum for the finite-element models, were also examined. Contour plots of the predicted contact pressure distribution for the models at the acetabular component-bone interface and the bearing surface were obtained. The predicted maximum von Mises stresses and contact pressures experienced at the articulating surfaces for all the models were also given.

In order to determine the approximate deformation of the acetabular component, the positions of four arbitrary nodes on its rim, located along its axis, were noted in their unloaded state. The positions of these nodes were also recorded after press-fitting and loading. The approximate deformation was determined from the displacement calculation, which was taken to be the difference in the nodal position before and after loading.

\section{Results}

The total area of the acetabular component surface experiencing micromovement less than $50 \mu \mathrm{m}$ was shown to be significant, with approximately $80 \%$ of the contact surface of the press-fit and the line-to-line models experiencing micromovement below this threshold value (Fig. 3a). Whereas the maximum relative micromovement for the press-fit models was less than $10 \mu \mathrm{m}$, the maximum micro- 


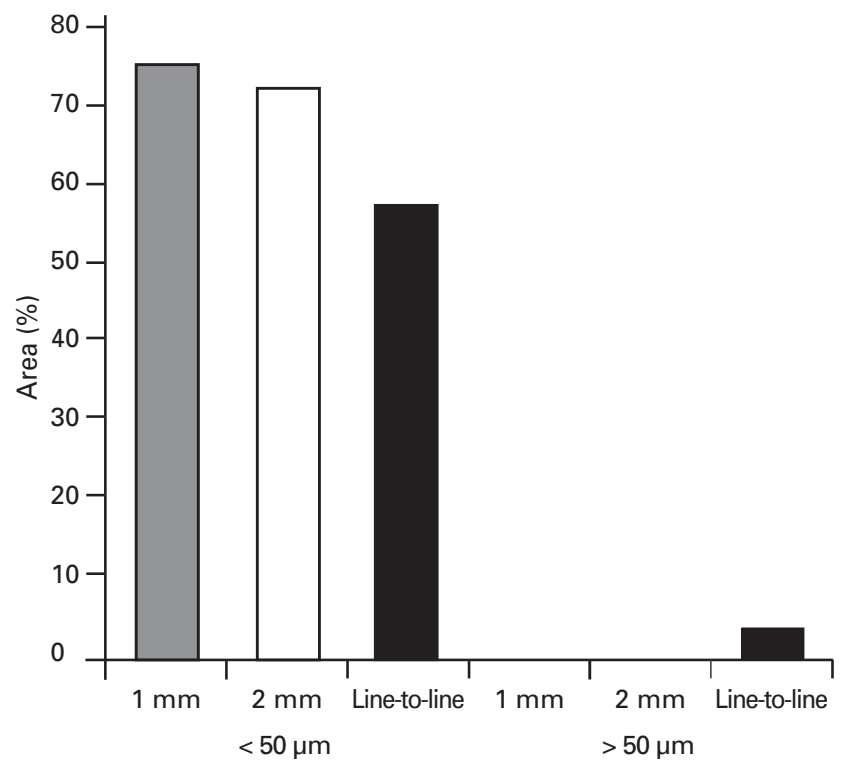

Fig. 3a

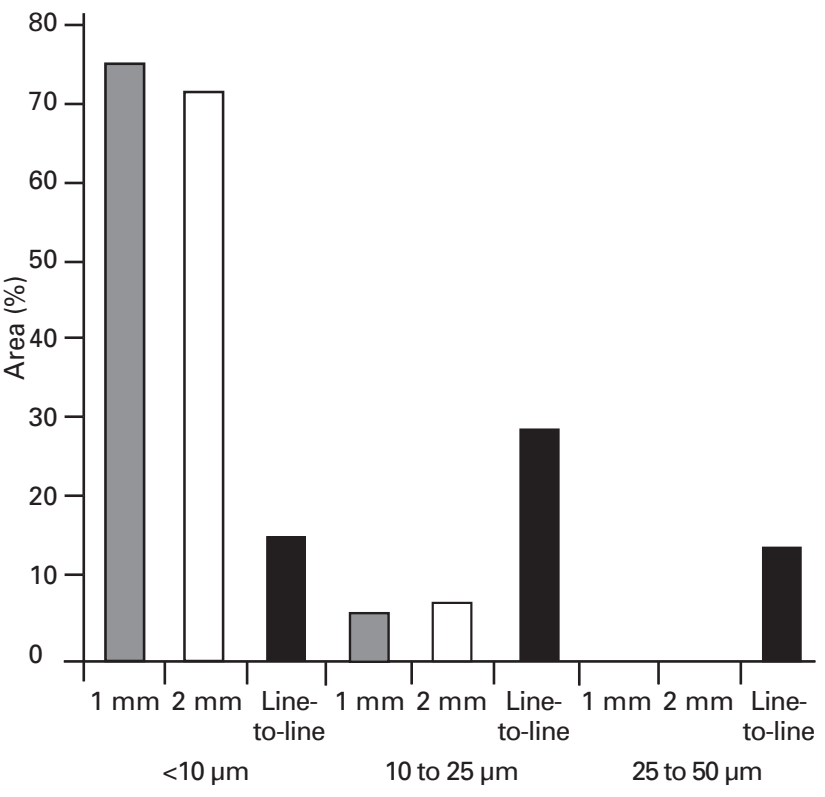

Fig. 3b

A comparison of the approximate percentage area of the acetabular component experiencing a) relative micromovement at the cup-bone interface, and b) less than the $50 \mu \mathrm{m}$ threshold required for osseointegration.

Table I. Comparison of the predicted maximum relative micromovement between the acetabular component and the bone, contact parameters at the acetabular component-bone interface, and the maximum von Mises stress in the acetabulum for the finite-element (FE) cup models

\begin{tabular}{lcllc}
\hline FE model & $\begin{array}{l}\text { Maximum micromove- } \\
\text { ment }(\mu \mathbf{m})\end{array}$ & $\begin{array}{l}\text { Maximum contact pressure } \\
(\mathbf{M P a})\end{array}$ & $\begin{array}{l}\text { Total contact area } \\
\left(\mathbf{m m}^{2}\right)\end{array}$ & $\begin{array}{l}\text { Maximum von Mises } \\
\text { stress }(\mathrm{MPa})\end{array}$ \\
\hline $1 \mathrm{~mm}$ press-fit & 6.8 & 24.3 & 3772 & 67 \\
2 mm press-fit & 5.9 & 53.6 & 3647 & 125 \\
Line-to-line & 60.1 & 7.3 & 3219 & 22.2 \\
Fully bonded & $\mathrm{NA}^{*}$ & $\mathrm{NA}$ & $\mathrm{NA}$ & 22.4 \\
\hline
\end{tabular}

* NA, not applicable

movement for the line-to-line model was approximately $60 \mu \mathrm{m}$ (Table I). The distribution of the total percentage contact area experiencing micromovement less than $50 \mu \mathrm{m}$ is shown in Figure $3 \mathrm{~b}$. Over $70 \%$ of the contact area experienced micromovement under $10 \mu \mathrm{m}$ for the press-fit models whereas $15 \%, 28 \%$ and $13 \%$ experienced micromovement under $10 \mu \mathrm{m}$, between $10 \mu \mathrm{m}$ and $25 \mu \mathrm{m}$, andbetween $25 \mu \mathrm{m}$ and $50 \mu \mathrm{m}$ respectively, for the line-to-line acetabular components (Fig. 3b).

The contact between the acetabular component and the bone for the press-fit models occurred predominantly about the periphery of the acetabulum, as shown in the contour plots of the contact pressure distribution (Fig. 4). However, for the line-to-line model, contact appeared to be distributed across the acetabulum. A significant sevenfold increase in the predicted maximum contact pressure at the acetabular component-bone interface was noted between the line-to-line and the $2 \mathrm{~mm}$ press-fit models (Table I), with an approximate twofold increase in the predicted maximum contact pressure between the $1 \mathrm{~mm}$ and $2 \mathrm{~mm}$ inter- ference press-fit models. The corresponding reduction in the total contact area between these two models was 3\%.

Increasing the diametral interference also resulted in significant increases in the acetabular stresses. An approximate six-fold increase in the maximum von Mises stress was observed between the line-to-line and the $2 \mathrm{~mm}$ press-fit models (Table I). There was negligible difference in the acetabular stress between the line-toline model and the fully-bonded model.

A moderate reduction in the predicted maximum contact pressure by approximately $30 \%$ was observed as the interference was increased from a line-to-line fit to the 2 $\mathrm{mm}$ press-fit model (Fig. 5). This reduction in contact pressure was accompanied by a corresponding increase in the predicted total contact area by up to $40 \%$. Comparison between the $2 \mathrm{~mm}$ press-fit model and the fullybonded model showed an approximately $35 \%$ increase in the maximum contact pressure (Table II) and a corresponding $53 \%$ reduction in contact area. 


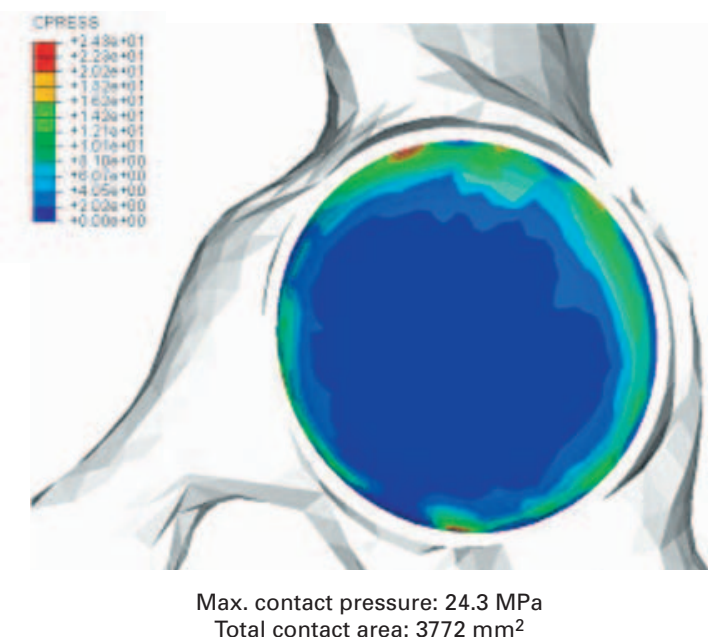

Fig. $4 \mathrm{a}$

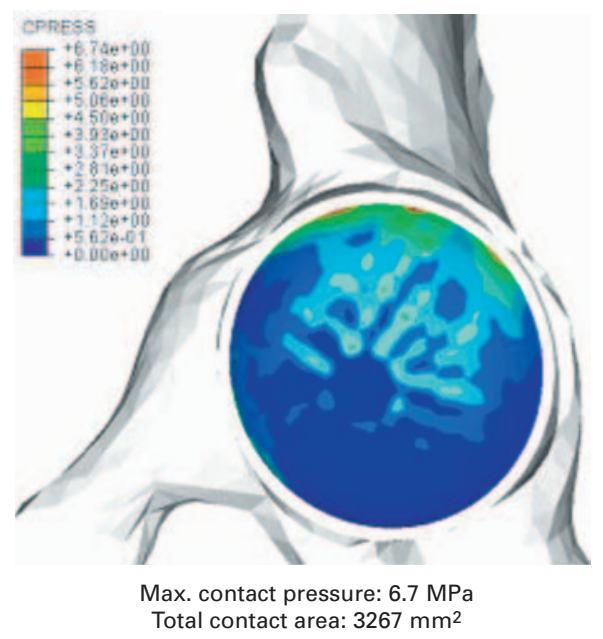

Fig. 4c

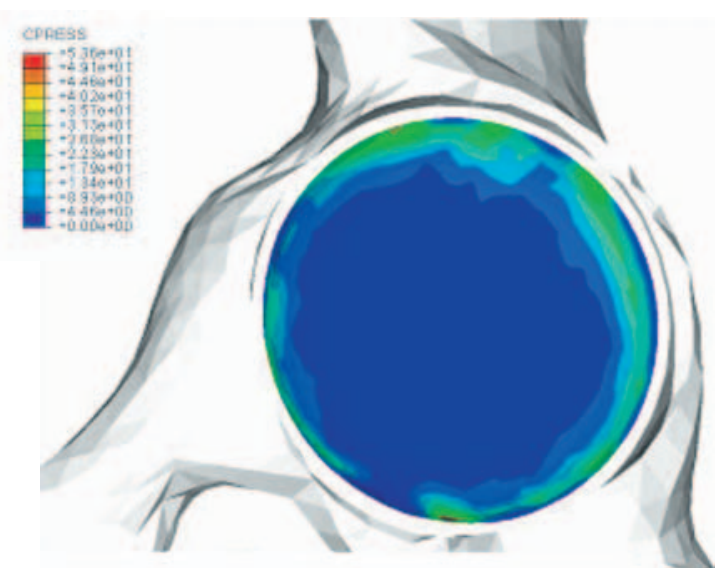

Max. contact pressure: $53.6 \mathrm{MPa}$ Total contact area: $3647 \mathrm{~mm}^{2}$

Fig. $4 b$

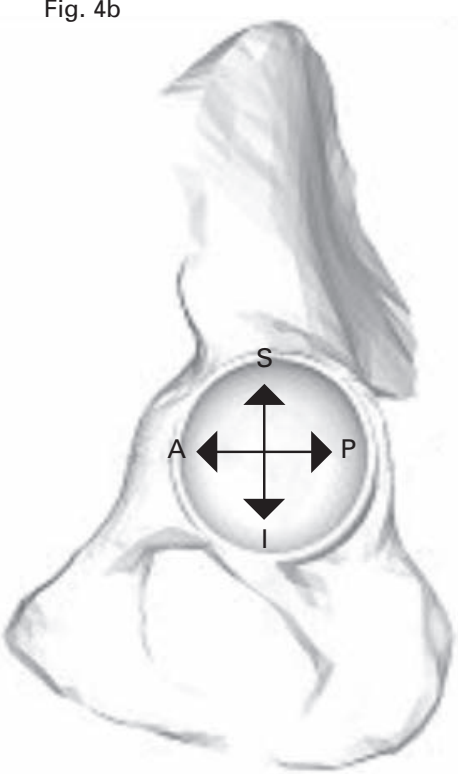

Fig. 4d

Contour plot showing a comparison of the predicted contact pressure distribution at the cup-bone interface for a) the $1 \mathrm{~mm}$ press-fit model and b) the $2 \mathrm{~mm}$ press-fit model and c) the line-to-line model. d) Diagram showing the direction from which the contour plot of the acetabulum is viewed.

The compressive forces generated as a result of the pressfit procedure created significant deformation of the component. A comparison of the approximate radial deformation in the anteroposterior and superoinferior directions is shown in Table II for the different finite-element models. Increasing the interference resulted in a corresponding rise in radial deformation, particularly in the superoinferior direction.

\section{Discussion}

The stability of cementless acetabular components used in total hip replacement has been well documented. ${ }^{12,15,17,23,24,46-48}$ However, little has been reported on the stability, tribology and contact interaction across the fixation at the bearing surfaces in the large-diameter metal- lic monoblock components used in hip resurfacing. The stability of a metal-on-metal hip resurfacing arthroplasty was examined in the present study by determining the total relative micromovement between the acetabular components and the acetabular surfaces. The predicted contact area at this interface occurred over approximately $87 \%, 84 \%$ and $75 \%$ of the total surface area of the acetabulum for the 1 $\mathrm{mm}$ press-fit, $2 \mathrm{~mm}$ press-fit and line-to-line cups, respectively (Table I). Of this, the total percentage area experiencing micromovement below the $50 \mu \mathrm{m}$ threshold required for bone ingrowth, was found to be just over $71 \%$ for the press-fit cup models and approximately $56 \%$ for the lineto-line reamed model. Studies have shown that relative displacements between implant and bone of less than $50 \mu \mathrm{m}$ tend to encourage osseointegration, whereas displacements 


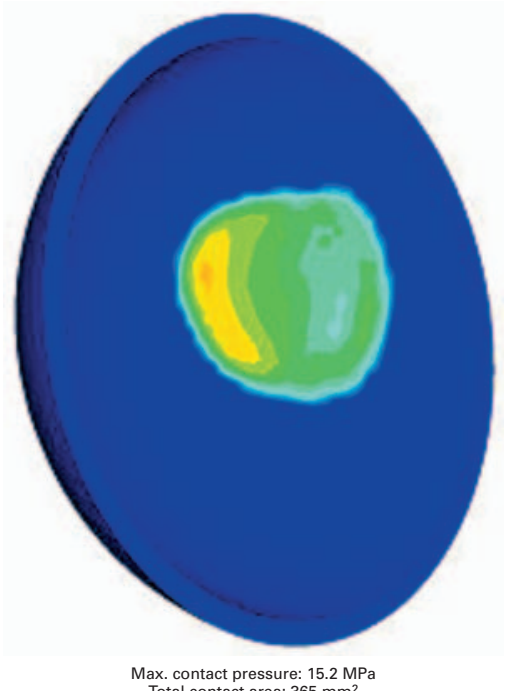

Fig. $5 a$

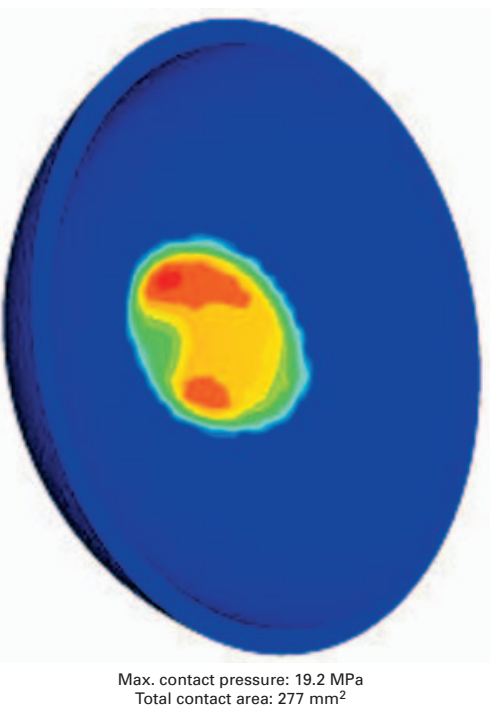

Fig. 5d

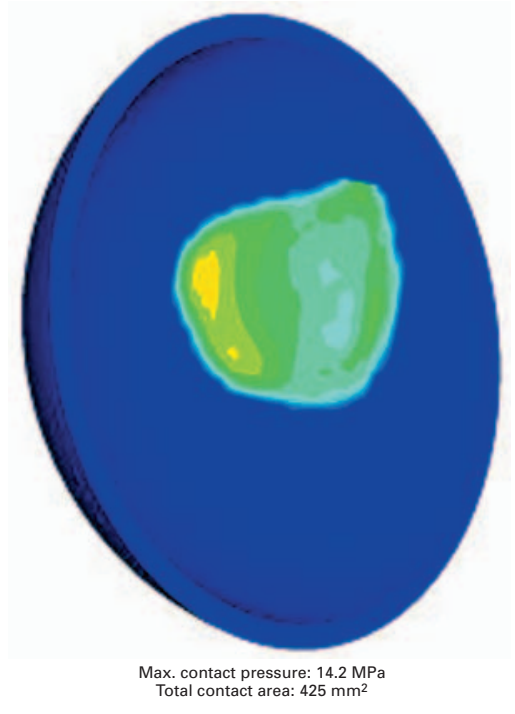

Fig. 5b

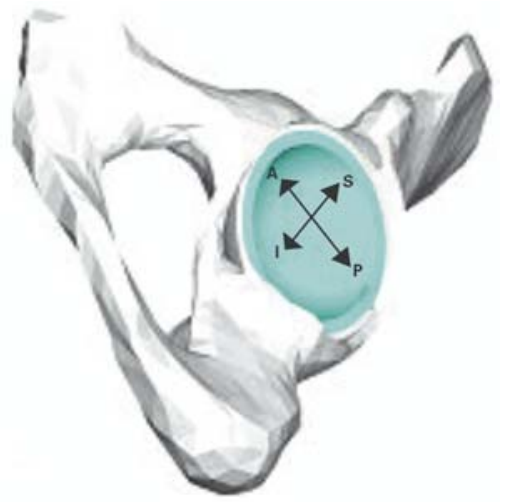

Fig. 5e

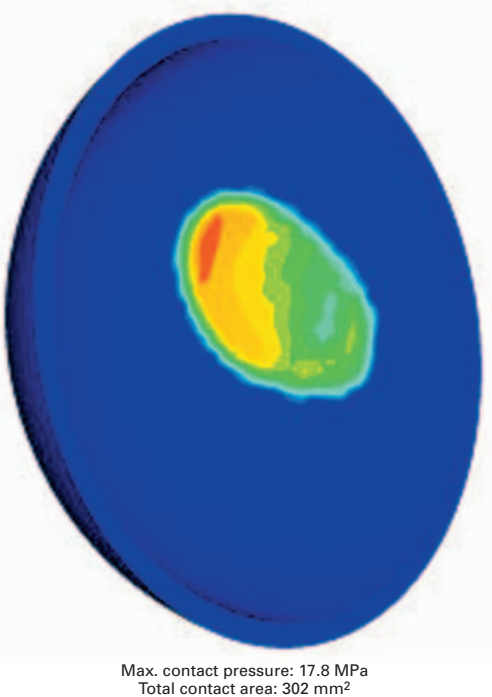

Fig. 5c

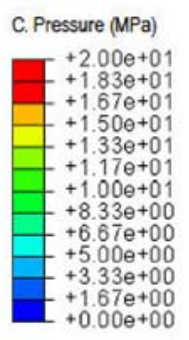

Contour plot showing a comparison of the predicted contact pressure distribution at the bearing surfaces for a) the $1 \mathrm{~mm}$ press-fit model, b) the $2 \mathrm{~mm}$ press-fit model, c) the line-toline model and d) the fully bonded model. e) The direction from which the contour plot in the acetabular cup is viewed.

greater than $50 \mu \mathrm{m}$ impede bone ingrowth. ${ }^{49-53}$ This therefore suggests that all the models considered would provide adequate conditions for ingrowth. However, the press-fit acetabular components would provide the more ideal conditions required for initial stability than the line-to-line model. For the latter, only approximately $5 \%$ of the contact area experienced micromovement above $50 \mu \mathrm{m}$. Bone ingrowth would be possible in this case in some areas; but, it might be impeded by fibrous tissue growth in other areas, increasing the risk of late implant loosening. ${ }^{50,51}$ It must be noted that the line-to-line model considered in this study did not include adjunctive fixation, as may not be the case clinically. Adjunctive fixation, such as screws or peripheral cup fins, would further limit the relative micromovement between the implant and the bone for both the line-to-line and the press-fit cup models.

The reduction of relative micromovement in the press-fit models was largely due to increased compressive and frictional stresses generated in the acetabulum, which provided the load transfer across the interface between the acetabular component and the bone needed to hold and secure the cup and to resist micromovement. The acetabular stresses were found to increase significantly as the interference was increased. Such stresses could potentially be damaging to the supporting bone or any potentially out-growing bone tissue. ${ }^{25,54}$ However, it must be noted that the finite-element 
Table II. Comparison of the predicted maximum contact parameters at the bearing surfaces and the approximate deflection at the rim of the acetabular component in the anteroposterior and superoinferior directions for the finite-element (FE) models

\begin{tabular}{lllll}
\hline & & & \multicolumn{2}{c}{ Deflection at cup rim $(\mu \mathbf{m})$} \\
\cline { 3 - 5 } FE model & Maximum contact pressure $(\mathbf{M P a})$ & $\begin{array}{l}\text { Total contact area } \\
\left(\mathbf{m m}^{2}\right)\end{array}$ & Anteroposterior direction & \multicolumn{2}{c}{$\begin{array}{c}\text { Superoinferior direc- } \\
\text { tion }\end{array}$} \\
\hline $1 \mathrm{~mm}$ press-fit & 15.2 & 365 & 24.4 & 48.7 \\
$2 \mathrm{~mm}$ press-fit & 14.2 & 425 & 45.3 & 94.6 \\
Line-to-line & 17.8 & 302 & 69.4 & 7.5 \\
Fully bonded & 19.2 & 277 & 21.9 & 9.9 \\
\hline
\end{tabular}

model used in the study did not consider the heterogeneous nature and the viscoelastic, time-dependent behaviour of the cancellous bone. In the clinical situation, consideration of these properties would result in stress reduction and the relaxation of the bone surrounding the implant. ${ }^{55-57}$ Instead, for this study, the bone was assumed to be homogeneous and linear elastic. This would add to the overall rigidity in the finite-element models and the over-estimation of the stresses predicted. ${ }^{20,55}$ This model therefore gives a qualitative, rather than a quantitative evaluation of the predicted stresses. Viscoelastic finite-element models of bone are not readily available in the literature; however, a recent study demonstrated similar behaviour in the predicted results between homogeneous linear elastic and heterogeneous finite-element models. ${ }^{33}$ This further justifies the homogeneous, linear elastic models used in the present study. ${ }^{32,34,35}$ Furthermore, this study only simulated the immediate post-operative situation, and the predicted results represent a possible worst-case mechanical scenario due to the material property assumptions, although not clinically relevant in terms of in vivo simulation.

Design and manufacturing parameters, such as diametral clearance, femoral head diameter and surface roughness, have been shown to significantly influence the contact mechanics and tribology at the bearing surfaces of hip resurfacing prostheses. ${ }^{26,36,58}$ The effect of the press-fit procedure on the contact mechanics at the bearing surfaces for a metal-on-metal hip resurfacing arthroplasty was examined. Increasing the interference resulted in a moderate reduction in the predicted contact pressure, which can be largely attributed to the increased contact area and acetabular component/femoral head conformity. However, there was a significant increase in deformation of the acetabular component as the interference was increased (Table II). No edge contact was identified, although it was shown that increasing the interference resulted in a twofold increase in the approximate deformation of the acetabular component in the anteroposterior and superoinferior directions for the press-fit models. Deformation in the superoinferior direction was found to be greater than in the anteroposterior direction. The anteroposterior direction experienced greater compression and coincided with the acetabular regions, reinforced anterosuperiorly by the bodies of the ilium and pubis, and posteroinferiorly by the body of the ischium. The superoinferior direction corresponded to bony regions about the acetabulum that were less stressed, which resulted in these regions experiencing expansion into the acetabular notch.

The predicted deformation about the rim of the acetabular component was up to $65 \%$ with increasing interference, and could possibly result in edge contact should the interference be further increased. Edge contact could potentially result in lubricant starvation and increased wear generation; however, no edge contact was found for the press-fit models in this study. The anteroposterior deformation for the line-to-line fully-bonded models showed greater values than in the superoinferior direction, a different trend from that observed for the press-fit models. This was largely due to anteroposterior translation, with the line-to-line model undergoing more translation. The predictions of deformation in the present study were found to compare qualitatively with recent experimental and finite-element studies. ${ }^{59,60}$

Factors such as poor bone quality due to age or disease could influence both the initial and the long-term stability of resurfacing arthroplasties. In such cases, the deterioration and reduction in bone-tissue properties could significantly increase the risk of fracture or loosening. ${ }^{61-63}$ However, for the conditions considered in the present study, the results suggest that provided the acetabulum is mechanically sound, press-fit acetabular components between $1 \mathrm{~mm}$ and $2 \mathrm{~mm}$ should have adequate fixation for initial post-operative stability. This study further reinforces previous clinical and experimental findings on the importance of press-fit fixation on establishing initial implant stability.

The authors wish to thank the Arthritis Research Campaign (ARC), UK, for financial support.

One or more of the authors have received or will receive benefits for personal or professional use from a commercial party related directly or indirectly to the subject of this article.

\section{References}

1. Kishida Y, Sugano N, Nishii T, et al. Preservation of the bone mineral density of the femur after surface replacement of the hip. J Bone Joint Surg [Br] 2004;86-B:1859.

2. Treacy RBC, McBryde CW, Pynsent PB. Birmingham hip resurfacing arthroplasty: a minimum follow-up of five years. J Bone Joint Surg [Br] 2005;87-B:167-70.

3. Daniel J, Pynsent PB, McMinn DJ. Metal-on-metal resurfacing of the hip in patients under the age of 55 years with osteoarthritis. J Bone Joint Surg [Br] 2004;86B:177-84.

4. Itayem R, Arndt A, Lundberg A, Nistor L, McMinn D. Stability of the Birmingham hip resurfacing arthroplasty at two years: a radiostereophotogrammetric analysis study. J Bone Joint Surg [Br] 2005;87-B:158-62.

5. Amstutz HC, Grigoris P, Dorey FJ. Evolution and future of surface replacement of the hip. J Orthop Sci 1998;3:169-86. 
6. Noble P, Paravic V, Ismaily S. Are big heads the solution to dislocation after total hip replacement? Procs 48th Annual Meeting of the Orthopaedic Research Society, 2002.

7. Schmalzried TP, Fowble VA, Ure KJ, Amstutz HC. Metal on metal surface replacement of the hip: technique, fixation and early results. Clin Orthop 1996;329(Suppl):10614

8. de Smet KA, Pattyn C, Verdonk R. Early results of primary Birmingham hip resurfacing using a hybrid metal-on-metal couple. Hip Int 2002;12:158-62.

9. Amstutz HC, Beaule PE, Dorey FJ, et al. Metal-on-metal hybrid surface arthroplasty: two to six-year follow-up study. J Bone Joint Surg [Am] 2004;86-A:28-39.

10. Back DL, Dalziel R, Young D, Shimmin A. Early results of primary Birmingham hip resurfacings: an independent study of the first 230 hips. J Bone Joint Surg [Br] 2005;87B:324-9.

11. Grigoris P, Roberts P, Panousis $K$, Bosch $\mathbf{H}$. The evolution of hip resurfacing arthroplasty. Orthop Clin North Am 2005;36:125-34.

12. Morscher EW. Current status of acetabular fixation in primary total hip arthroplasty. Clin Orthop 1992;274:172-93

13. Muller U, Gautier E, Roeder C, Busato A. The relationship between cup design and the radiological signs of aseptic loosening in total hip arthroplasty. J Bone Joint Surg [Br] 2003;85-B:31-6.

14. Glyn-Jones S, Gill HS, McLardy-Smith P, Murray DW. Roentgen stereophotogrammetric analysis of the Birmingham hip resurfacing arthroplasty: a two-year study. Bone Joint Surg [Br] 2004;86-B:172-6.

15. Manley MT, Capello WN, D'Antonio JA, Edidin AA, Geesink RGT. Fixation of acetabular cups without cement in total hip arthroplasty: a comparison of three different implant surfaces at a minimum duration of follow-up of five years. J Bone Joint Surg [Am]1998;80-A:1175-85

16. Adler E, Stuchin SA, Kummer FJ. Stability of press-fit acetabular cups. J Arthroplasty 1992; 7:295-301.

17. Ries MD, Harbaugh M, Shea J, Lambert R. Effect of cementless acetabular cup geometry on strain distribution and press-fit stability. J Arthroplasty 1997;12:207-12.

18. Widmer K-H, Zurfluh B, Morscher EW. Load transfer and fixation mode of press-fit acetabular sockets. J Arthroplasty 2002;17:926-35.

19. Won C-H, Hearn TC, Tile M. Micromotion of cementless hemispherical acetabula components: does press-fit need adjunctive screw fixation? J Bone Joint Surg $[\mathrm{Br}$ 1995;77-B:484-9

20. McKenzie JR, Callaghan JJ, Pedersen DR, Brown TD. Areas of contact and exten of gaps with implantation of oversized acetabular components in total hip arthroplasty. Clin Orthop 1994:298:127-36.

21. Spears IR, Morlock MM, Pfleiderer M, Schneider E, Hille E. The influence of friction and interference on the seating of a hemispherical press-fit cup: a finite element investigation. J Biomech 1999:32:1183-9.

22. Amstutz HC, Campbell PA, Duff MJ. Fracture of the neck of the femur after surface arthroplasty of the hip. J Bone Joint Surg [Am] 2004;86-A:1874-7.

23. Morscher E. Principles of acetabular fixation in THR with special reference to the "press-fit cup". Acta Orthopaedica Belgica 1993;59(Suppl 1):260-6.

24. Kwong LM, O'Connor DO, Sedlacek RC, et al. A quantitiative in vitro assessment of fit and screw fixation on the stability of a cementless hemispherical acetabular component. J Arthroplasty 1994:9:163-70.

25. Curtis MJ, Jinnah RH, Wilson VD, Hungerford DS. The initial stability of uncemented acetabular components. J Bone Joint Surg [Br] 1992;74-B:372-6.

26. Udofia IJ, Jin ZM. Contact mechanics analysis of metal-on-metal hip resurfacing prostheses. Proc Inst Mech Eng [H] 2004;218:293-305

27. Thompson MS, Northmore-Ball MD, Tanner KE. Effects of acetabular resurfacing component material and fixation on the strain distribution in the pelvis. Proc Inst Mech [H] 2002;216:237-45.

28. Huiskes R, Strens P, Vroemen W, Slooff TJ. Post-loosening mechanical behavior of femoral resurfacing prostheses. Clin Materials 1990;6:37-55.

29. Visible Human Project. http://www.nlm.nih.gov/research/visible/ visible_human.html (date last accessed February 2005).

30. Viceconti M, Casali M, Massari B, et al. The 'standardized femur program' proposal for a reference geometry to be used for the creation of finite element models of the femur. J Biomech 1996;29:1241.

31. Augat $\mathbf{P}$, Link $T$, Lang TF, et al. Anisotropy of the elastic modulus of trabecular bone specimens from different anatomical locations. Med Eng Phys 1998;20:124.

32. Mann KA, Bartel DL, Wright TM, Burstein AH. Coulomb frictional interfaces in modeling cemented total hip replacements: a more realistic model. J Biomech 1995;28:1067-78

33. Shultz TR, Blaha JD, Gruen TA, Normal TL. Cortical bone viscoelasticity and fixation strength of press-fit femoral stems: a finite element model. J Biomech Eng 2006;128:7 12.

34. Spears IR, Pfleiderer M, Schneider E, Hille E, Morlock MM. The effect of interfacial parameters on cup-bone relative micromotions: a finite element investigation. J Biomech 2001:34:113-20.
35. Tai C-L, Shih C-H, Chen W-P, et al. Finite element analysis of the cervico-trochanteric stemless femoral prosthesis. Clin Biomech 2003;18:53-8.

36. Liu F, Udofia IJ, Jin ZM, et al. Comparison of contact mechanics between a total hip replacement and a hip resurfacing with a metal-on-metal articulation. Procs I Mech E Journal of Mechanical Engineering Science Part C 2005:727-32.

37. Shirazi-AdI A, Dammak M, Paiement G. Experimental determination of friction characteristics at the trabecular bone/porous-coated metal interface in cementless implants. J Biomed Mater Res 1993;27:167-75.

38. Rancourt D, Shirazi-AdI A, Drouin G, Paiement G. Friction properties of the interface between porous-surfaced metals and tibial cancellous bone. J Biomed Mater Res 1990;24:1503-19.

39. Shybut GT, Askew MJ, Hori RY, Stulberg SD. Theoretical and experimental studies of femoral stresses following surface replacement hip arthroplasty. Proc Inst Med Chic 1980;33:95-106

40. Munting $\mathbf{E}$, Verhelpen $\mathbf{M}$. Fixation and effect on bone strain pattern of a stemless hip prosthesis. J Biomech 1995;28:949-61.

41. Huiskes R, Strens PH, van Heck J, Slooff TJ. Interface stresses in the resurfaced hip finite element analysis of load transmission in the femoral head. Acta Orthop Scand 1985:56:474-8.

42. Bergmann G, Graichen F, Rohlmann A. Hip joint loading during walking and running, measured in two patients. J Biomech 1993;26:969-90.

43. Duda GN, Schneider E, Chao EYS. Internal forces and moments in the femur during walking. J Biomech 1997:30:933-41.

44. Duda GN, Brand D, Freitag S, Lierse W, Schneider E. Variability of femoral muscle attachments. J Biomech 1996;29:1185-90.

45. Spears IR, Pfleiderer M, Schneider E, et al. Interfacial conditions between a pressfit acetabular cup and bone during daily activities: implications for achieving bone ingrowth. J Biomech 2000;33:1471-7.

46. Engh CA, Griffin WL, Marx CL. Cementless acetabular components. J Bone Joint Surg [Br] 1990;72-B:53-9.

47. Perona PG, Lawrence J, Paprosky WG, Patwardhan AG, Sartori M. Acetabular micromotion as a measure of initial implant stability in primary hip arthroplasty: an in vitro comparison of different methods of initial acetabular component fixation. J Arthroplasty 1992;7:537-47

48. Dowdy PA, Rorabeck CH, Bourne RB. Uncemented total hip arthroplasty in patients 50 years of age or younger. J Arthroplasty 1997;12:853-62.

49. Pilliar RM, Lee JM, Maniatopoulos C. Observations on the effect of movement on bone ingrowth into porous-surfaced implants. Clin Orthop 1986;208:108-13.

50. Kienapfel H, Sprey C, Wilke A, Griss P. Implant fixation by bone ingrowth. J Arthroplasty 1999;14:355-68.

51. Jasty M, Bragdon C, Burke D, et al. In vivo skeletal responses to porous-surfaced implants subjected to small induced motions. J Bone Joint Surg [Am]1997;79-A:707-14.

52. Krismer M, Stockl B, Fischer M, et al. Early migration predicts late aseptic failure of hip sockets. J Bone Joint Surg [Br] 1996;78-B:422-6.

53. Bloebaum RD, Mihalopoulus NL, Jensen JW, Dorr LD. Postmortem analysis of bone growth into porous-coated acetabular components. J Bone Joint Surg [Am] 1997:79-A:1013-22.

54. Ramamurti BS, Orr TE, Bragdon CR, et al. Factors influencing stability at the interface between a porous surface and cancellous bone: a finite element analysis of a canine in vivo micromotion experiment. J Biomed Mater Res 1997;36:274-80.

55. Larsson S, Elloy M, Hansson LI. Fixation of trochanteric hip fractures: a cadaver study of static and dynamic loading. Acta Orthop Scand 1987;58:365-8.

56. Shultz TR, Normal TL, Gruen TA, Blaha JD. The effects of cortical bone viscoelasticity on the short-term fixation of press-fit cylindrical intramedullary rods. Procs ASME International Mechanical Engineering Congress and Exhibition, 2002: American Society of Mechanical Engineers.

57. Norman TL, Ackerman ES, Smith TS, et al. Cortical bone viscoelasticity and fixation strength of press-fit femoral stems: an in-vitro model. J Biomech Eng 2006;128:13-17.

58. Udofia IJ, Jin ZM. Elastohydrodynamic lubrication analysis of metal-on-metal hipresurfacing prostheses. J Biomech 2003;36:537-44.

59. Lin ZM, Meakins S, Morlock MM, et al. Deformation of press-fitted metallic resurfacing cups. Part 1: experimental simulation. Proc Inst Mech Eng [H]2006;220:299-309.

60. Yew A, Jin ZM, Donn A, Morlock MM, Isaac G. Deformation of press-fitted metallic resurfacing cups. Part 2: finite element simulation. Proc Inst Mech Eng [H] 2006;220:311-19.

61. Kobayashi S, Saito N, Horiuchi H, lorio R, Takaoka K. Poor bone quality or hip structure as risk factors affecting survival of total-hip arthroplasty. Lancet 2000;355:1499-504.

62. Graham J, Ries M, Pruitt L. Effect of bone porosity on the mechanical integrity of the bone-cement interface. J Bone Joint Surg [Am]2003;85-A:1901-8.

63. Zioupos P, Currey JD. Changes in the stiffness, strength and toughness of human cortical bone with age. Bone 1998:22:57-66. 